\title{
A Modular and Extensible Framework for Human Resource System
}

\author{
Muhammad Zabir Abdul Halim, Marshima Mohd Rosli \\ Department of Computer Science, Faculty of Computer and Mathematical Sciences, \\ Universiti Teknologi MARA, Shah Alam, Selangor, Malaysia
}

\section{Article Info \\ Article history: \\ Received May 11, 2018 \\ Revised Jul 12, 2018 \\ Accepted Jul 26, 2018}

\section{Keywords:}

Framework

Human Resource Management

Performance

Productivity

System

Technology

\begin{abstract}
Human Resource is an essential part for an organization and integration of technology would just enhance the effectiveness. One of the scope that Human Resource must take note is performance and productivity. However, there is still no infallible or highly reliable way to measure productivity and performance of an organization and its employees for current industrial Human Resource systems. There is still possible improvement that can be made to the system in the current time. The purpose of this study is to propose a modular and extensible framework of Human Resource systems that used to measure the performance and productivity of an organization. This study compares the different criteria of existing Human Resource systems to ensure the proposed framework would surpassed the current real world industrial system. The results of the review provide insights for important criteria in HR system to increase the accuracy of the performance review. This study also constructs Entity Relationship Diagram (ERD) to demonstrate the logical structure of the proposed framework. The ERD will form the foundation of the proposed framework to improve the Human Resource system for evaluating the productivity and performance of an organization.
\end{abstract}

Copyright $\odot 2018$ Institute of Advanced Engineering and Science. All rights reserved.

\section{Corresponding Author:}

Muhammad Zabir Abdul Halim,

Department of Computer Science,

Faculty of Computer and Mathematical Sciences,

Universiti Teknologi MARA, Shah Alam, Selangor, Malaysia.

Email: tsonouichi@gmail.com

\section{INTRODUCTION}

The emergence usage of technology in many domains is not rare and uncommon within the era of Industrial 4.0. As mentioned by Kagermann H., technology would be the main driver and motivation of innovation and improvement in all domains [1]. Sensitive domains or highly technical domains such as banking and manufacturing are also into the usage of technology to assist in carrying out tasks with assurance of higher efficiency and effectiveness. Some use cases use technology to reduce operation cost and maintainability. However, is inevitable to state that there are consequences of adopting the dependency of technology. Nevertheless, the positive impact surpasses the consequences that many domains adopting it without any hesitant.

Human Resource (HR) domain would not fall behind and began to adopt technology. There are lots of system created to support HR tasks from various organizations. According to Stone et al., HR has adopted the usage of technology and demonstrate huge impact on the HR practices and processes [2,3]. HR is responsible to manage and organize the resources that related to employee. The example of the tasks is managing the resource of employees, salary and events. Hence, it is a must have domain. The HR tasks are distressingly hard. It is quite common to make a mistake due to workload difficulty and the impact would be huge. Thus, an organization could not afford to bear mistakes constantly when dealing with HR task. 
The adoption to technology is to reduce those problems. Usually the information technology system created to just store all the information regarding the employee's details including work related information. Certain advanced system adopted the use of employee information to be use as variables for metrics in evaluating the performance or productivity of the organization. According to DeNisi et al, there are many of HR methods that can be used in evaluating the performance and productivity [3].

The purpose of this study is to compare existing HR system and propose a better extensible framework that can be attached into most existing HR management system. Preferably this system would be a platform that can be used in any HR practices and is not rigid. The focus of the comparison in this study would be the criteria that affects the performance review.

According to Stone et al, the usage of technology in HR cause the communication to be interpersonal and creates artificial distance between employee and supervisor that would result in hard to gain proper reviews and advices [2], [4], [5]. This shows current HR systems do not cater important aspects that the result of the accuracy for the reviews on performance to be questionable. The example would be the transparency difference business nature between departments of all levels. Hence, that is the gap that is being highlighted in this research. In addition, there are not much research being done on the improvement of HR management system for performance review. The gap between academic research and industrial movement on this matter is getting wider. Industrial corporate considering this matter as a priority while academic research lack of that awareness. This study will propose a framework that will fill the gap to increase the accuracy of the review and academic research to not falling behind with the industrial improvement. Furthermore, this study can be a clear indicator that the area contains gap that can be filled with further research and development. Is a great possibility this matter can be improved even further.

\section{CRITERIA}

This section focusing on important criteria that would affect greatly on the performance evaluation. These criteria might be correlate with each other or standalone. Nevertheless, the more criteria present the higher the capability to yield better accuracy in the evaluation. There are six criteria that will be investigated.

First, goal driven approach which refer to the performance will be evaluated on the person capability to complete the task within the constraint applied. This is quite common usually on many organization as it is simple but effective. As mentioned by Murphy et al., there is a testimony that indicate goal driven approach or management by objective benefit to productivity though it depends on the management support on it [5]. It is easier to organize as this type of approach able to apply in many difficult situations such as multiple branches and internalization that would give a hard time for higher up to meet and monitor the employees and give the evaluation. In addition, this type of approach works very well with most of domain available. For example, Information Technology (IT) domain which programmers will be given issues to be solved within certain deadline and if the programmers able to solve hence, it is considered a good performance. In addition, this approach would vanquish most of bias that traditional evaluation would arise such as manager give good evaluation to the employees that he knows and liked very well despite the task done are worse than other employees.

According to Murphy et al, the evaluator has the tendency to be dishonest on the evaluation [5]. This approach would investigate what the employee had done and able to compare all employees with same standard. Thus, the evaluation would have a concrete justification. Moreover, this approach allow standardization to happen as every employee will be reviewed in the same manner with the same metrics [7].

Second, would be the assessment and feedback approach which refer to comments or thoughts given by the supervisor at every task done by the employees. This approach been adopted by many of small sized company and branch internally. This is because every employee knows each other very well and east of monitor the progression of employee. This approach is great at identifying the weakness or problem at the root as fast as possible. Thus, would be able to discuss and suggest the best alternative to solve the problem that the employee face. The faster blockers and problems solved, the faster employees can get things done. Thus, it would elevate the productivity greatly. Furthermore, it would avoid the presence of virtual distance that usually the lower level employee felt with higher level employee and would result in hesitation to ask important and relevant question that could demote productivity. As stated by London et al., feedback with given with the right information will affects the performance appraisal and review [5]. However, there is a flaw with this approach which occurs when the organization becomes medium or big sized company. When organization grow bigger and add more level between employees, the higher level could not evaluate every lower level. Thereupon, would put trust on other people evaluation and no way to justify the truth on that evaluation. For instance, the person in charge give evaluation to employees dishonestly, the higher up would not aware of the dishonest committed and would simply trust the evaluation. This would create an unfair and non-progressive judgement to the employees. Thus, it disrupts the productivity. 
Third, the role management which refers to management of responsibilities and scope of work. Every organisation must adopt this as roles are important as it is the definition of the employee's work. Before any employee begin to perform their work, they will need to clearly understand their scope of work and impact to the organisation. This is to avoid any unnecessary clash of responsibilities and waste of efforts made by the employees. According to Kerzner et al., without proper management of professional responsibilities, it may lead to clash of interest between the employees [8]. Stating clearly between employees regarding their roles can be a good justification on their work completed and avoid any thought of task given by the organization as bias. Hence, role is important that could affect the productivity. Furthermore, the role can define the employees' focus on their career advancement. Employee that be given the right role would perform better as they are doing what they love and good at. This can avoid the thought of being forced to complete the task. Thus, able to maintain the mental healthiness of the employees. They are more prone to do extra then they should if they are mentally happy. Besides that, roles can assist in categorizing and differentiate goals and objectives that the employees must achieve. Not every employee holds the same type of goals. For example, programmers achieve goals by completing issues while sales marketers by getting amounts of client to join in. Hence, differentiate suitable goals and objective between employees is a good way to standardize it in a fair manner.

Fourth, transparency which refers to non-existence of abstraction between employees especially with employees from different levels. This criterion would make the communication to be more open and direct. In addition, there is no façade that would deny any false speculation or guessing that would just avoid any unnecessary trouble and problem. Any suggestion and problem can be issue directly without too much procedural steps that would just cut to the chase and avoid waste of time. Furthermore, it can be a great platform for defence of your own right if there is any judgement or review errors and discuss to get mutual agreement between the evaluator and employee. This would increase the accuracy of the performance review. However, according to the study conducted by Sumelius et al., many organization adopting the transparency but lack of real practice in the organization [10]. This result in bad impact and impression that many would thought the performance review to be waste of time as does not yield satisfactory result. So, this criterion must be fully committed to bear any good result out of it.

Fifth, customizable which refers to the flexibility configuration that able to be applied. Every organization does not have the similarity structure, business logic and management. It is impossible to standardize every domain into one standard way to be governed. Hence, if there is only one rigid way to perform the evaluation of performance, organizations will be forced to use it despite the ineffectiveness and inaccurate due to unsuitability towards the organization's business nature. This is unfavourable and cannot be accepted with current modern age that promotes varieties of business nature to rise. Thus, every organization need to be able to customize their own governance of performance review, so it suits their business nature and able to yield better accuracy of review. According to the study conducted by Åhlström and Westbrook, customization able to improve the operations [11]. However, as high it can be, it is wise to create boundaries within the customization as to avoid the basic and necessity component in performance review to cease. It is important to still maintain the basic component of performance review to ensure the result is trustable and within the standard as Human Resource domain has set.

Sixth, prediction which refers to the assessment results of the information gathered to be used for future planning. As time goes by, an organization and its employees would grow into certain extent. Management must be aware of this fact and perfectly plan the best alternative approach in getting the most optimized growth out of it. However, the growth of the organization does not necessarily would result in growth of its employees but if there are growth in its employees it will automatically result in growth of the organization [9]. Thus, is not alright for management to only thought of the growth of organization alone. In addition, the employees would maintain the mental healthiness due to their interest are being considered and would perceive that they are an asset to the organization. Hence, the turnover rate for that organization would drop for a certain extent. That is how important to take note on the growth of the employees. Prediction or assessment would be required by the management to look forward of the direction for both the organization and its employees. The best result would be both grow adjacently. There are many of models, framework and methods that can be used to assess. Nevertheless, prediction requires ample of time and data to be able to present meaningful knowledge. A study conducted by Allen et al., in education domain to predict students' achievements by using scoring system indicated that the relationship between teacher and student plays huge factor [12]. The study also indicates it does requires ample of time and data for the results to come fruition. Hence, this can be applied in this study as well that it is a requirement if desire to use this criterion. However, need to take note that prediction and assessment are not entirely correct as there are many of uncertainties that is hard to identify and insert into the assessment. It only serves as a parameter to plan for the next step. 


\section{REVIEW OF HR SYSTEMS}

In this section, this study observed and reviewed industrial HRM systems that being used by many organizations in their implementation of these criteria. This study also studied three systems which are ClearCompany HRM, Kronos Workforce Ready and BambooHR.

\subsection{ClearCompany HRM}

ClearCompany HRM is a system developed by ClearCompany. ClearCompany is a company that originally founded in 2004 as HRM Direct. Founded by Django Bliss, Andre Lavoie and Colin Kingsbury. The company focus on developing and maintaining system that focus on cloud-based talent management. The location of their offices is located at Boston, Fort Collins and San Francisco.

ClearCompany HRM is a system focused and proud of their Talent Management feature, but they do have features that caters the performance review. It caters a lot of industries such as education, energy and financial. The approach that implement in ClearCompany HRM is goal driven approach as they keep track on the employees' work done and evaluate from that point. The essential part which is role management is implemented. Transparency between employees is enabled. Other than that, the performance review is fully customizable to suit based on business use case of the organization. 9-box reporting is the scoring method that being implemented where it determines by two major factors which are potential and performance. This type of score method is easy to understand and to plot the data. However, there are no presence on the prediction feature on the performance review.

\subsection{Kronos Workforce Ready}

Next, Kronos Workforce Ready is a system developed by a company named Kronos. It was announced and delivered in 2012 by the current Chief Editorial Officer (CEO) of Kronos, Aron Ain. Kronos founded by a Massachusetts Institute of Technology (MIT) alumni, Mark Ain, in 1977 which created the industry's first microprocessors-based time clock as their first product. Currently, Kronos focus on the workforce management and human capital management. The location of the headquarters currently at Lowell, Mass.

Kronos Workforce Ready is a system focused on workforce management. There are lots of modules that can be used and only cherry-pick the required modules. All the modules will be treated as one whole system for Kronos Workforce Ready. The approach that implement in Kronos is similar with ClearCompany HRM which is goal driven approach. Like ClearCompany HRM, Kronos Workforce Ready implements role management and transparency in the system. Scoring map used in the system to determine the score of the employee which specified by the organization. Scoring map is a bit complex than 9-box reporting as it need to depend on calculation, but it is more informative. However, it did not implement customizable as you need to rigidly follow how the system does the workflow. In addition, it did not implement prediction feature on the performance review.

\subsection{BambooHR}

Lastly, BambooHR is a system developed by Bamboo. Bamboo is a company founded in 2008 by Ben Peterson and Ryan Sanders. BambooHR is their main product. Has been developed and still maintain since the company created. Currently, the company located in Lindon, Utah.

BambooHR is a system that focus in assist organization in dealing with basic HR tasks. Compared with two other systems, BambooHR have the least features. Nevertheless, for the performance review, BambooHR implement similar features to ClearCompany which implements role management, transparency and customizable but with different approach. BambooHR's approach is assessment and feedback approach which supervisor of the task will always return feedback of the task done. Feedback also would be the main key to indicate the employee's score. Unfortunately, like both other systems, there is no prediction feature implemented in the performance review.

Table 1. Comparative Table of HRM Systems. It shows all three HRM Systems that been reviewed on all criteria mentioned

\begin{tabular}{lccccccc}
\hline Software & \multicolumn{8}{c}{ Criteria } & \multicolumn{1}{c}{ Method } \\
& $\mathbf{1}$ & $\mathbf{2}$ & $\mathbf{3}$ & $\mathbf{4}$ & $\mathbf{5}$ & $\mathbf{6}$ & \\
\hline ClearCompany & $\checkmark$ & $\checkmark$ & $\times$ & $\checkmark$ & $\checkmark$ & $\checkmark$ & 9 Box \\
vamboOHR & $\checkmark$ & $\times$ & $\checkmark$ & $\checkmark$ & $\checkmark$ & $\times$ & Feedback \\
\hline
\end{tabular}


Table 1 shows the comparative table of HRM Systems. Based on this table, we can see that three matured HRM systems is good but can still be improved as there are criteria that they did not implement. Every system has their own strength and advantage.

\section{PROPOSED FRAMEWORK}

As we had reviewed the important criteria in HR system that would affect the performance review, this study would like to propose a modular and extensible framework that can be applied in HRM, shown Figure 1. The proposed framework would apply the whole criteria to optimise the performance review. Hence, the architecture of the framework must support the whole criteria. This study constructs Entity Relationship Diagram (ERD) to demonstrate the logical structure of the proposed framework to be achievable.

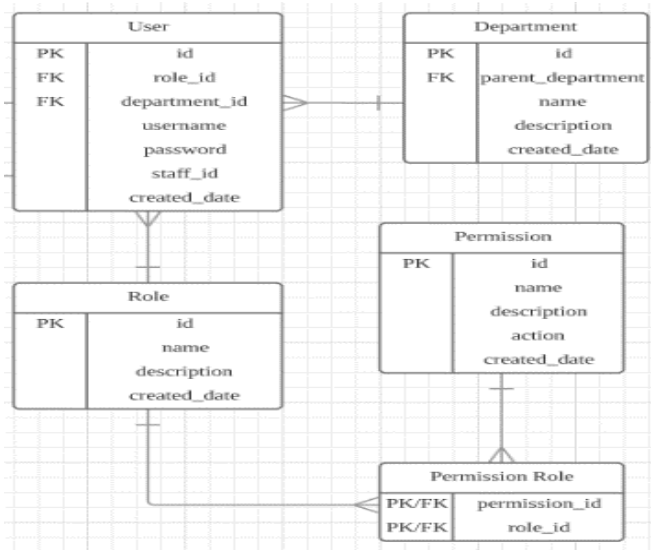

Figure. 1. Shows the first part of the ERD where it caters the criteria of role management and customization in the HRM

There are four entities involved which are User, Department, Permission and Role. User is the representation of employee, Role is the representation of position and Department is the representation of group of employees. A User would have a Role and Department that can be assigned to. Department and Role can have multiple User can assign to them. Department can be set as multiple level dynamically. Permission holds the authorization over the actions that can be made and page that can be viewed. Role will be tight to Permission as the use case for certain role can only perform certain action and view certain page. The organization must set their own User, Role, Permission and Department as they see fit. The modal allows the customization over role management to be suitable for every type of organization.

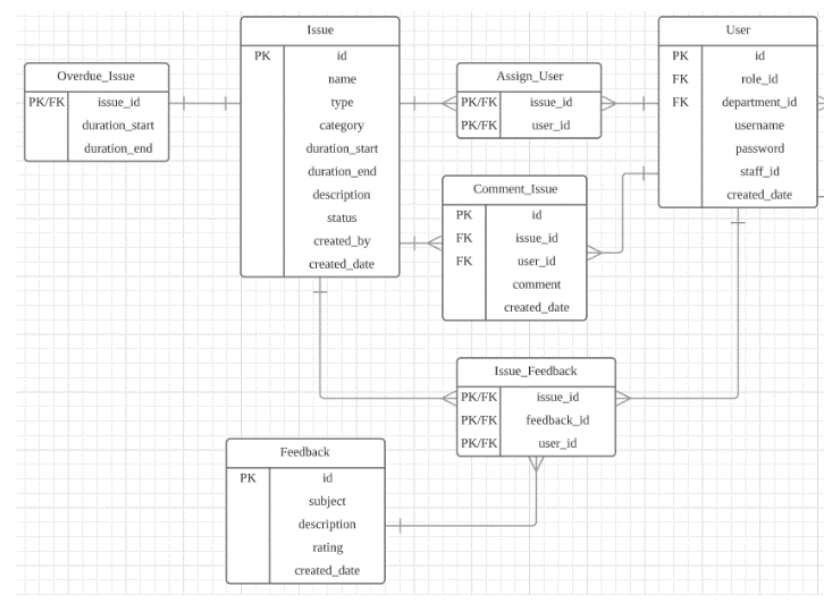

Figure. 2. Shows the second part of the ERD where it caters the goal driven, feedback driven, customization and transparency criteria in the HRM 
There are five entities involved which are User, Issue, Feedback, Comment Issue and Overdue Issue. Issue is the representation of task or goal for employees, Feedback is the representation of the task's assessment, Comment Issue is the representation space to have a discussion between employee regarding the task and Overdue Issue is the representation of task that been delayed by employees. Multiple User can be assigned to multiple Issue while able to give multiple Feedback at the same time. Multiple User able to comment on multiple Issue for a discussion or enquiries. Any delayed issue will be recorded to Overdue Issue. This allows the organization keep track of the tasks being delivered on time or not while giving a transparency to comment and assess the tasks done by employees by their supervisors. The organization will set their own type and category of the Issue as they see fit. This will allow the customization over the creation of Issue to be suitable for the organization's use case.

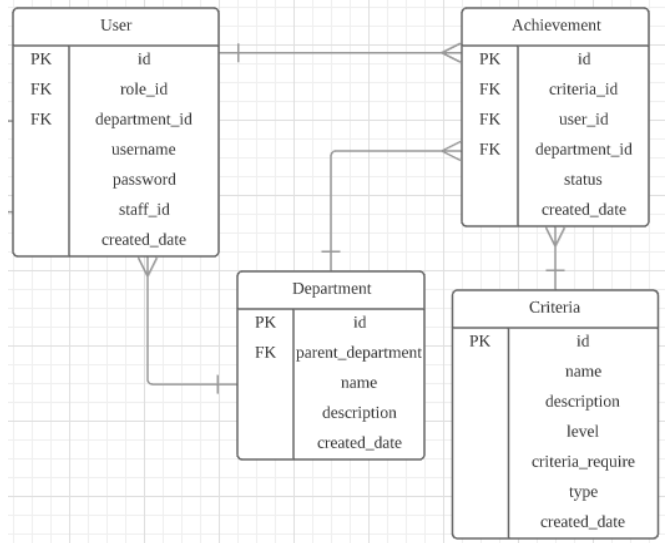

Figure 3. Shows the third part of the ERD where it caters the criteria of prediction and customization in HRM.

There are two entities involved which are User, Department, Achievement and Criteria. Criteria is the representation of both the achievement and the requirement to achieve. Achievement holds the record of any achievement obtained by the departments and employees. Multiple User and multiple Department able to achieve multiple achievement. The organization must set their own criteria. The organization able to set it as a prediction or as a present achievement. This allows the organization to implement their own modals of prediction and achievements as every organization has their own researched design prediction and achievements.

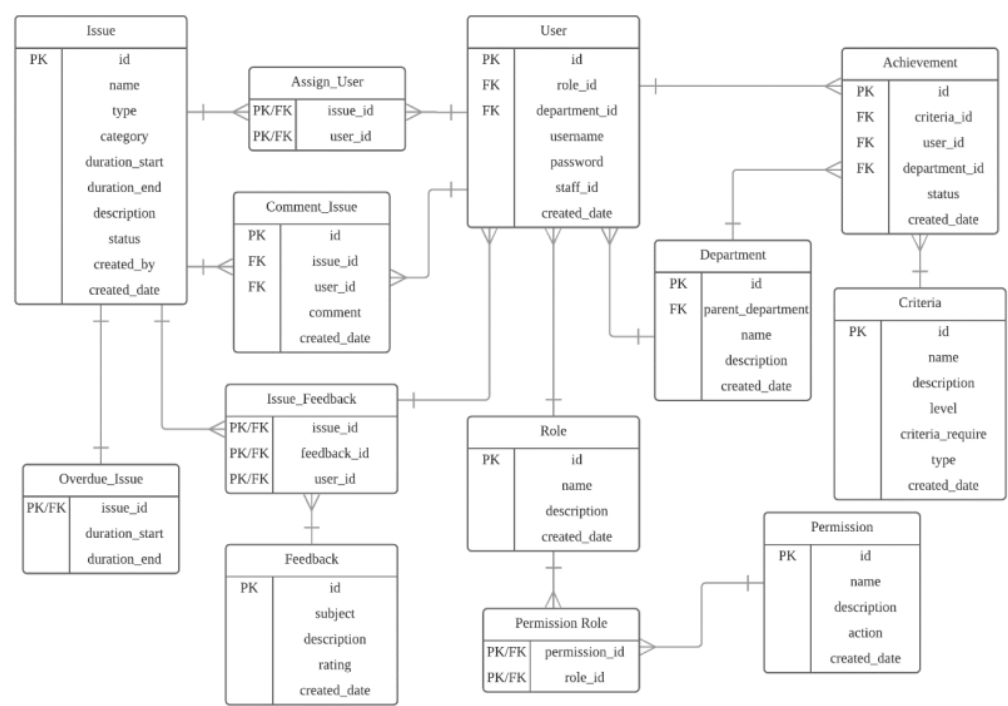

Figure. 4. Shows the overall of the ERD for this study's proposed framework. 
The proposed framework can be implemented in other way but ultimately the important criteria must be implemented in the HRM system. This study aware that certain existing HR system has already implement certain criteria in the system. So, they do not deliberately have to create another module that would be redundant but just update the system to implement the missing criteria. This framework can also be an extensible modular that develop in such a way that could be plug and play into any HR system. Hence, it can be an optional choice for the organization to include or not the criteria in the HR system.

\section{CONCLUSION}

This study set out to compare existing HR system and propose a modular and extensible framework that can be implemented in the HR system and can be used by HR management. Ultimately, this study has identified six important criteria to be implemented in the HR system for performance review. These criteria are goal driven, feedback driven, role management, transparency, customization and prediction. The results of the review on current HR systems indicate that the awareness of current HR system did not implement certain criteria that would boost the performance review accuracy and effectiveness. This prove that there is a wide gap in perfecting the performance review in HR system. The proposed framework utilize fully on those criteria and it must be acceptable by various type of organisations. Hence, this study hope that the proposed framework would be able to facilitate and compress the gap of the performance review of HRM system in effectiveness and accuracy in any organisations.

\section{ACKNOWLEDGEMENTS}

The authors would like to thank the Ministry of Education Malaysia and Universiti Teknologi Mara for their financial support to this project under FRGS Grant No. FRGS/1/2016/ICT01/UITM/02/3.

\section{REFERENCES}

[1] Kagermann, H. (2015). Change through digitization-Value creation in the age of Industry 4.0. In Management of permanent change (pp. 23-45). Springer Gabler, Wiesbaden.

[2] Stone, D. L., Deadrick, D. L., Lukaszewski, K. M., \& Johnson, R. (2015). The influence of technology on the future of human resource management. Human Resource Management Review, 25(2), 216-231.

[3] Yusuf, S. U., Taslim, J., Wan Adnan, W. A., \& Baharudin, S. K. (2015). Usability evaluation of Human Resource Management Information System (HRMIS). In Proceedings - 2014 3rd International Conference on User Science and Engineering: Experience. Engineer. Engage, i-USEr 2014 (pp. 204-209). [7002703] Institute of Electrical and Electronics Engineers.

[4] DeNisi, A., \& Smith, C. E. (2014). Performance appraisal, performance management, and firm-level performance: A review, a proposed model, and new directions for future research. The Academy of Management Annals, 8(1), 127-179.

[5] Murphy, K. R., \& Cleveland, J. N. (1995). Understanding performance appraisal: Social, organizational, and goalbased perspectives. Sage.

[6] London, M., \& Smither, J. W. (1995). Can multi-source feedback change perceptions of goal accomplishment, selfevaluations, and performance-related outcomes? Theory-based applications and directions for research. Personnel Psychology, 48(4), 803-839.

[7] Janom, N., Md Nordin, N. F., \& Aris, S. R. S. (2013). Evaluating user satisfaction of Veteran Integrated Benefit System (VIBES) in Jabatan Hal Ehwal Veteran (JHEV). In International Conference on Research and Innovation in Information Systems, ICRIIS (pp. 457-462). [6716753]

[8] Kerzner, H., \& Kerzner, H. R. (2017). Project management: a systems approach to planning, scheduling, and controlling. John Wiley \& Sons.

[9] Talib, R., Ismail, R., Janor, R. M., Azni, Z. A., \& Aljunid, S. Y. E. D. A. B. D. U. L. K. A. D. E. R. (1999). Programme quality assessment by the implication of variable entry qualifications on students' performance. Assessment and Evaluation in Higher Education, 24(2), 205-213.

[10] Sumelius, J., Björkman, I., Ehrnrooth, M., Mäkelä, K., \& Smale, A. (2014). What determines employee perceptions of HRM process features? The case of performance appraisal in MNC subsidiaries. Human Resource Management, 53(4), 569-592.

[11] Åhlström, P., \& Westbrook, R. (1999). Implications of mass customization for operations management: an exploratory survey. International Journal of Operations \& Production Management, 19(3), 262-275.

[12] Allen, J., Gregory, A., Mikami, A., Lun, J., Hamre, B., \& Pianta, R. (2013). Observations of effective teacherstudent interactions in secondary school classrooms: Predicting student achievement with the classroom assessment scoring system-Secondary. School Psychology Review, 42(1), 76.

[13] Talent Acquisition and Talent Management Software | ClearCompany. (n.d.). Retrieved April 10, 2018, from https://www.clearcompany.com/

[14] Workforce Ready Suite. (n.d.). Retrieved April 10, 2018, from https://www.kronos.com/products/workforce-readysuite

[15] Bamboo Testimonial. (n.d.). Retrieved April 10, 2018, from https://www.bamboohr.com/ 